\title{
THE SYNTAX OF WHETHER/Q .. OR QUESTIONS: ELLIPSIS COMBINED WITH MOVEMENT *
}

\begin{abstract}
In this paper, we argue that the syntax of whether $/ Q \ldots$ or questions involves both movement of whether $/ Q$ and ellipsis of the type that has been argued to exist for either $\ldots$ or constructions. Three arguments are presented: (i) English whether/Q ... or questions present at the same time movement characteristics (sensitivity to islands) and ellipsis traits (focus pattern on the disjuncts); (ii) crosslinguistic data on the surface string syntax of Subject-Object-Verb (SOV) languages support the ellipsis plus movement account in general and, thus, indirectly also for English; and (iii) certain asymmetries between whether/Q...or and either...or are resolved, permitting a unified account of the two types of constructions.
\end{abstract}

\section{INTRODUCTION}

In English, a question may have a disjunctive phrase explicitly providing the choices that the question ranges over. For example, in (1), the disjunction or not indicates that the choice is between the positive and the negative polarity for the relevant proposition, as spelled out in the yes/no (yn)question reading (2) and in the answers (2a,b). Another example is (3). The disjunction in (3) can be understood as providing the choices that the question ranges over, hence giving rise to the alternative (alt-)reading in (4) and eliciting the answers in (4a,b) (cf. Karttunen 1977 and Higginbotham 1993 for the semantics of $y n /$ alt-questions).

(1) Did John eat beans or not?

(2) $y n$-reading: "Is it true or false that John ate beans?"

a. Yes, John ate beans.

$\star$ We thank Rajesh Bhatt for extensive discussion on several aspects of this paper. This paper has also benefitted from discussions and comments at various stages from Lorna Fadden, Nancy Hedberg, Tony Kroch, Dean Mellow, Bill Poser, Beatrice Santorini, and the audiences at NELS 32 and the Dept. of Linguistics colloquium at Simon Fraser University in Fall 2001. We also wish to thank the anonymous reviewers for their critical comments that helped us reshape and improve this paper. All remaining errors are ours. Finally, Han acknowledges SSHRC Standard Research Grant \#410-2003-0544 for support when this paper was written. 
b. No, John didn't eat beans.

(3) Did John eat beans or rice?

(4) alt-reading: "Which of these two things did John eat: beans or rice?"

a. John ate beans.

b. John ate rice.

Questions with an associated disjunction phrase can also occur, of course, in embedded contexts. (5) and (6) are the embedded counterparts of (1) and (3) respectively, with the indicated relevant readings:

(5) I wonder [whether John ate beans or not].

a. $y n$-reading: "I wonder whether it is true or false that John ate beans."

(6) I wonder [whether John ate beans or rice].

a. alt-reading: "I wonder which of these two things John ate: beans or rice."

The syntax of questions with an overt associated disjunction phrase is the topic of this paper. Note that (3) and (6) also have a $y n$-reading, spelled out in (7). Under this reading, the question choice does not range over the overt disjuncts beans and rice, but over a positive and negative polarity not explicitly expressed. The derivation of this $y n$-question reading without an overt associated disjunction is beyond the scope of this paper; however, in section 6.2, we will briefly sketch possible analyses of it that are compatible with the main claims of this paper.

(7) $\quad y n$-reading for (3) and (6):

"Is it true or false that John ate any of these two things, beans or rice?"

a. Yes, John ate beans or rice.

b. No, John didn't eat beans or rice.

Throughout this paper, we will call both matrix and embedded questions with an associated disjunctive phrase "whether/Q ...or constructions'. $Q$ corresponds to covert whether. Positing a covert whether in matrix questions is motivated by the fact that there are languages that allow 
overt whether in matrix $y n$ - or alt-questions. Examples from Early Modern English and Yiddish are given in (8) and (9).

(8) Early Modern English (examples taken from Radford (1997, p. 295)

a. Whether had you rather lead mine eyes or eye your master's heels?

'Would you rather lead my eyes or eye your master's heels?' (Mrs. Page, Merry Wives of Windsor, III.ii)

b. Whether dost thou profess thyself a knave or a fool?

'Do you profess yourself (to be) a knave (= scoundrel) or a fool?' (Lafeu, All's Well that Ends Well, IV.v)

(9) Yiddish

a. (Tsi) reykhert Miryam?

whether smokes Miryam

'Does Miryam smoke?'

b. Shmuel hot mikh gefregt, tsi Miryam reykhert.

Shmuel has me asked whether Miryam smokes

'Shmuel asked me whether Miryam smokes'.

There have been two main approaches to the syntax of disjunctive $O p$ erator ... or constructions in the literature. Larson (1985) assimilates the syntax of whether/ $Q \ldots$ or constructions to either ... or constructions as in (10), arguing that in both, either or whether/Q is base-generated adjacent to the disjunctive phrase and that it undergoes movement.

(10) Either John ate beans or rice.

Schwarz (1999), on the other hand, showed that the syntax of either ... or can be accounted for better if we assume that the second disjunct is a clause with a particular type of ellipsis, namely gapping. Unfortunately, he was not able to extend the ellipsis analysis to whether $Q$... or, because he found certain asymmetries between whether/Q $\ldots$ or structures and the type of ellipsis allowed in either... or.

In this paper, we propose that the syntax of whether/Q $\ldots$ or questions involves ellipsis of the type that has been argued to exist for either ... or constructions, as illustrated in (11). We also argue, with Larson, that whether/Q undergoes movement. The representation of alt-questions that 
we will defend in this paper is illustrated in (12). We attribute the apparent asymmetries between whether/Q $\ldots$ or and either ...or constructions to the fact that whether/Q is a $w h$-phrase that can undergo movement, while either is not.

(11)a. Either John ate beans or rice.

b. Either [John ate beans] or [John ate rice]

(12)a. (Q/whether) did John eat beans or rice?

b. (Q/whether $)_{i}$ did $t_{i}$ [John eat beans] or [John eat rice]

Three arguments for our combined ellipsis/movement analysis of whether/Q ... or questions will be presented: (i) English whether/Q ... or questions present at the same time movement characteristics (sensitivity to islands) and traits that follow naturally under an ellipsis account (focus pattern on the disjuncts); (ii) crosslinguistic data on the surface string syntax of Subject-Object-Verb (SOV) languages show that alt-readings involve ellipsis and movement (or a parallel scoping mechanism) in these languages, hence indirectly supporting the same analysis for English; (iii) finally, Schwarz's asymmetries between whether/Q ... or and either ... or in English are resolved, permitting a unified account of the two types of constructions.

This paper is organized as follows. In sections 2 and 3, we will briefly present the main points of Larson's movement account and Schwarz's ellipsis account. We will then further argue that whether/Q is a wh-phrase undergoing movement to [Spec, $\mathrm{CP}$ ], in section 4. This movement is subject to island constraints, just like any other $w h$-movement. In section 5 , we argue that in conjunction with whether/Q-movement, whether/Q ... or questions involve ellipsis of the type that has been argued to exist for either...or declaratives. Just as in either... or declaratives, ellipsis in whether $Q$ Q...or questions is constrained to be restricted to a finite clause. Our main argument for ellipsis in whether/Q ... or questions will come from languages with canonical SOV word order - Hindi and Korean. We will also argue that the focus pattern found in English alt-questions can only be given a natural explanation under the ellipsis account. In section 6 , we show how the combination of whether/Q-movement and ellipsis derives English alt-questions, thereby giving a unified account of either ... or and whether $/ Q \ldots$ or constructions as well as accounting for their asymmetries. We conclude with some discussion on whether/Q ... or questions involving right-node raising, in section 7 . 


\section{LARSON's MOVEMENT ACCOUNT}

According to Larson (1985), in sentences with either ... or, either originates adjacent to a disjunctive phrase, and moves to higher up in the clause, determining the scope of disjunction. For instance, in (13a), either originates adjacent to rice or beans, moving to the surface position adjacent to VP. In (13b), either originates adjacent to rice or beans, moving to the surface position adjacent to IP.

(13)a. John either ate rice or beans.

John either ${ }_{i}$ ate $t_{i}$ [NP rice] or [NP beans]

b. Either John ate rice or beans.

Either ${ }_{i}$ John ate $t_{i}$ [NP rice] or [NP beans]

Larson extends the movement analysis of either ... or constructions to whether $/ Q \ldots$ or questions. He argues that a question with associated disjunction has a question operator: whether or null $Q$. This operator originates from a disjunction phrase and moves to [Spec, CP], marking the scope of disjunction. Moreover, this type of question may have an overt or an unpronounced disjunction phrase or not. If the disjunction phrase from which the whether/ $Q$ originates is the overt or the unpronounced or not, then the $y n$-question reading is derived. Otherwise, the alt-question reading is derived. For instance, the question in (14) can have either a $y n$ question reading or an alt-question reading. Under the $y n$-question reading, the whether/Q operator originates from or not and moves to [Spec, CP], and the disjunction phrase coffee or tea is associated with another operator, as represented in (14a). Under the alt-question reading, the whether/ $Q$ operator originates from the disjunction phrase coffee or tea and moves to [Spec, CP], as represented in (14b).

(14) Did John drink coffee or tea?

a. $y$-question:

$\mathrm{Op}_{i}\left(t_{i}\right.$ or not) [did John drink [Op ${ }_{j}$ coffee or tea]] \{John drank coffee or tea, John didn't drink coffee or tea\}

b. alt-question:

$\mathrm{Op}_{i}$ [did John drink $\left[t_{i}\right.$ coffee or tea]]

$\{$ John drank coffee, John drank tea\}

As noted in Larson, supporting evidence for the proposal that whether/Q moves from a disjunction phrase to [Spec, $\mathrm{CP}]$ comes from 
the fact that questions that have the intended associated disjunction phrase inside an island do not have the alt-question reading available.

(15) Do you believe the claim that Bill resigned or retired?

a. $y n$-question:

$\mathrm{Op}_{i}\left(t_{i}\right.$ or not) [do you believe [NP the claim that Bill resigned or retired]]

b. *alt-question:

$\mathrm{Op}_{i}$ [do you believe $\left[_{\mathrm{NP}}\right.$ the claim that Bill $\left[t_{i}\right.$ resigned or retired]]]

In (15), the disjunctive phrase resigned or retired is inside a complex NP. The alt-question reading is not available since the empty operator would have to move out of an island to generate this reading, as represented in (15b). But the $y n$-question reading is available, since under this reading the empty operator is moving from the unpronounced or not, which is not inside an island. This reading is represented in (15a).

\section{SCHWARZ's ELLIPSIS ACCOUNT}

Schwarz (1999) argues that the syntax of either ... or constructions can be assimilated to the syntax of coordinate constructions that involve gapping, a type of ellipsis. Gapping originally refers to the grammatical process which is responsible for the deletion of a verb in the second coordinate of a conjunctive coordination under identity with the first coordinate, as in (16a) (Ross 1970). The deleted material in the second coordinate is called gap, and the materials in the second coordinate that have not been deleted are called remnants. Schwarz points out that gaps may contain more than just a verb, as shown in (16b), and argues that this fact is comparable with the idea that either... or constructions involve gapping.

(16)a. Tom has a pistol and Dick a sword.

[Tom has a pistol] and [Dick a sword]. (Schwarz 1999, ex. 30a)

b. Bill devoured the peaches quickly and Harry slowly.

[Bill devoured the peaches quickly] and

[Harry devoured the peaches slowly]. (Schwarz 1999, ex. 33a)

According to Schwarz, in either ... or constructions, either marks the left periphery of the first disjunct. This means that disjunctive declaratives with 
either occurring at the edge of a VP or an IP have VP or IP disjunctive structures, and so some materials in the second disjunct can be deleted under identity with the first disjunct. This is illustrated in (17). ${ }^{1}$

(17)a. John either ate rice or beans.

John either [vp ate rice] or [vp beans] (Schwarz 1999, ex. 28a)

b. Either John ate rice or beans.

Either [IP John ate rice] or [IP John ate beans] (Schwarz 1999, ex. 28b)

A compelling piece of supporting evidence for gapping analysis of either ... or constructions comes from unbalanced disjunction. It is generally accepted in the literature that the conjuncts in the Coordinate structure to which gapping applies must be parallel to each other (Hankamer 1971; Stillings 1975; Hudson 1976). If the parallelism constraint is violated, then the second conjunct would end up with a dangling remnant which lacks a correlate in the first conjunct. Schwarz notes that dangling remnants are prohibited in gapping constructions, as with me and clumsily in (18), and shows that they are prohibited in either ... or constructions as well, as off and $u p$ in (19).

(18)a. *Some talked about politics and others with me about music.

[some talked about politics] and [others with me about music]. (Schwarz 1999, ex. 40b)

b. ${ }^{*}$ John dropped the coffee and Mary clumsily the tea.

[John dropped the coffee] and [Mary clumsily tropped the tea]. (Schwarz 1999, ex. 41b)

(19)a.??Either this pissed Bill or Sue off.

Either [this pissed Bill] or [his Sue off]. (Schwarz 1999, ex. 43a)

\footnotetext{
${ }^{1}$ Given that gapping usually leaves more than one remnant, it might be surprising that Schwarz considers examples in (17) to be gapping constructions. Schwarz points out that there is no known argument to the effect that gapping must leave more than one remnant, and presents split coordinations, as in (i), as instances of gapping with one remnant, citing Hudson (1976), Neijt (1979), Reinhart (1991), and Johnson (1996).

(i)a. John bought a book yesterday, and a newspaper. (Schwarz 1999, ex. 36a)

b. John came, and Bill (too). (Schwarz 1999, ex. 36b)
} 
b.??Either they locked you or me up.

either [they locked you] or [he me up]. Schwarz 1999, ex. 43c)

Larson's movement account on the other hand has nothing to say about the fact that examples with dangling remnants are degraded.

Schwarz however did not extend the gapping analysis to alt-questions because gapping allowed in whether/Q $\ldots$ or constructions appears to be different from either ... or constructions. First of all, whether $/ Q$...or constructions seem to allow dangling remnants, unlike either ... or constructions and other coordinate constructions with gapping.

(20)a. Did this piss Bill or Sue off?

b. Did she turn the test or the homework in?

The questions in (20) can both have the alt-question reading. But if we were to apply the gapping analysis to these questions, then we would end up with dangling remnants, which were prohibited from other gapping constructions.

Second, whether/Q ...or constructions behave differently from other gapping constructions in that while elided materials cannot spread across matrix and embedded finite clauses, as shown in (21), they seem to be able to in whether/Q ... or constructions, as in (22).

(21)a. ${ }^{*}$ The first letter says that you should pay tax and the second letter V.A.T.

[The first letter says that you should pay tax] and [the second letter [tay [.A.T]]. (Schwarz 1999, ex. 61a)

b.??Either Bill said that Mary was drinking or playing video games. Either [Bill said that Mary was drinking] or

[Bill said [hat Mary playing video games].

(22)a. Did Bill say that Mary was drinking or playing video games?

b. Did John say that Bill retired or resigned?

c. Did John claim that Bill drank coffee or tea?

The questions in (22) all have the alt-question reading available. If this reading was derived via gapping in the second disjuncts in (22), then the ellipsis would spread beyond a finite clause boundary. But this is impossible in other gapping constructions. 
In sum, Larson defends a pure movement account of $O p \ldots$ or constructions and Schwarz proposes a pure ellipsis analysis of either ... or. We argue that both ellipsis and movement are needed to generate whether/Q $\ldots$ or questions. We claim that whether/ $Q$... or questions have a structure parallel to either ... or constructions, except for the additional fact that whether/Q moves to [Spec, $\mathrm{CP}]$. Our arguments for this combined movement/ellipsis approach are presented in the next two sections. In section 4 , we argue that whether is a wh-phrase and that, as such, it undergoes wh-movement. In section 5, we show that ellipsis is needed to explain the syntactic properties of alt-questions in SOV languages like Hindi and Korean, and that the focus intonation in English alt-questions follows naturally from an ellipsis account.

\section{Whether/Q IS A $w h$-PHRASE}

One compelling piece of evidence that supports the idea that whether is in $[\mathrm{Spec}, \mathrm{CP}]$ comes from the fact that there are languages that allow whether to cooccur with a complementizer. For example, this is attested in Middle English. The examples in (23) are from Penn-Helsinki Parsed Corpus of Middle English (Kroch and Taylor 2000).

(23)a. for men weten nou+gt whe+ter +tat he leue+t or is dede.

'For people don't know whether he is alive or is dead' (cmbrut3,90.2727)

b. and whe+ter +tat he shal ascape or dye, at Godes wil most hit be.

'and whether he escapes or dies, it must be according to God's will' (cmbrut3,107.3225)

c. aske hym whe+ter +tat er+te ys herre +ten Heuen?

'ask him whether Earth is higher than Heaven?' (cmmirk,10.273)

d. for Seynt Ierome sei+t whe+tur +tat he ete, drynke, or slepe, or what-euer els +tat he dothe,

'for Saint Jerome says that, whether he eats, drinks, or sleep;s, or whatever else that he does' (cmroyal,18.162)

e. it weere for to witen whether that alle thise thinges make or conjoynene as a maner body of blisfulnesse by diversite of parties or membres, ... 
'it would be to know whether all these things make or conjoin as a manner a body of blissfulness by diversity of parts or members ...' (cmboeth,433.C1.189)

It turns out that Middle English also allows a wh-phrase to cooccur with a complementizer, as in (24).

(24) First the behoueth to knowe why that suche a solitary lyf was ordeyned.

'First, it behooves thee to know why such a solitary life was ordained.' (cmaelr4-s0.m4,13)

b. ... he wiste wel hymself what that he wolde answere ...

'he himself knew well what he would answer' (cmctmelis0.m3,75)

c. Now shall ye understonde in what manere that synne wexeth or encreesseth in man.

'Now you shall understand in what manner sin grows or increases in man.' (cmctparss0.m3,390)

d. I pray you telle me what knyght that ye be

'Please tell me what knight you are' (cmmalory-20.m4,4655)

The same facts obtain in Belfast English (Alison Henry, p.c.).

(25)a. ?John wonders whether that Mary ate beans.

b. John wonders which sandwich that Mary ate.

This suggests that whether should not be classified as a complementizer, but as a $w h$-phrase, occupying [Spec, CP].

Furthermore, Larson (1985) points out, citing Jespersen (1909-1949), that whether developed historically as the wh-counterpart of either, and it originally meant 'which of either A or B'. If whether is a wh-phrase, it is reasonable to assume that it and its covert version $Q$ end up in [Spec, $\mathrm{CP}]$ by movement, just like any other $w h$-phrases. Moreover, just like any other wh-movement, whether/Q-movement is not clause-bound, but rather island-bound. The contrast in grammaticality between (26) and (27) illustrates this fact. The movement of $Q$ out of a complement clause is fine, hence the alt-reading in (26) is possible. But a complex NP is an island and so the movement of $Q$ in (27) is impossible, ruling out the alt-reading.

(26)a. Did John say that Bill resigned or retired? (alt-reading) 
b. $Q_{i}$ Did John say [that Bill $t_{i}$ [resigned or retired]]?

(27)a. *Did John believe the claim that Bill resigned or retired? (altreading)

b. ${ }^{*} Q_{i}$ Did John believe [the claim that Bill $t_{i}$ [resigned or retired]]?

\section{Ellipsis in Addition to Movement in Alt-Questions}

We have argued, in line with Larson (1985), that whether/Q moves from the left edge of the disjunction phrase to [Spec, CP], like $w$ h-phrases move. Once we allow whether/ $Q$-movement, it should be possible for an altquestion as in (28a) to have the parsing in (28b), where $Q$ is extracted from an NP disjunctive phrase, taking us back to the Larsonian derivation of $O p \ldots$ or constructions. After all, either can occur at the left edge of an $\mathrm{NP}$, marking an NP disjunction, as in (29). Hence, the source position for whether/Q in (28a) could very well be the position either occupies in (29).

(28)a. Did John drink coffee or tea?

b. $Q_{i}$ Did John drink $t_{i}$ [coffee or tea]

(29) John drank either [coffee or tea].

We have seen however in section 3 that a possible derivation for declaratives with or involves clausal disjunction, either at IP or VP level, with ellipsis in the second clause as in (30). ${ }^{2}$ Given the cross-categorial status of $o r$, if $o r$ can disjoin clauses in declaratives, there is no reason why it should not do so in questions. What this means is that in principle, for an alt-question as in (28a), the grammar would not only generate (28b), but also (31) with both movement of $Q$ and ellipsis in the second disjunctive clause.

(30) Either [John drank coffee or he drank tea].

$$
Q_{i} \text { Did } t_{i} \text { [John drink coffee or John drink tea]? }
$$

The question then is whether one derivation wins over the other, and if so, which one. In the next two subsections, we will provide arguments

\footnotetext{
2 Under the VP-internal subject hypothesis, VP is clausal.
} 
that support the derivation of the type in (31) - clausal disjunction plus ellipsis - for alt-questions. In subsection 5.1, we present evidence from cross-linguistic data that strongly supports our proposal that whether/Q ... or constructions involve disjunction at clausal level, IP or VP, with consequent ellipsis in the second clause. In subsection 5.2, we show that the focus pattern in alt-questions found in English can naturally be explained only under the ellipsis account.

\subsection{Cross-Linguistic Support}

Word order facts in languages that have canonical SOV word order provide evidence that the syntax of alt-questions involves clausal disjunction with ellipsis. We will examine two SOV languages here: Hindi and Korean. Moreover, scope marking data from Hindi supports the thesis that, besides ellipsis, a scoping mechanism is at work in alt-readings, just as in $w h$ questions. Finally, case marking in Korean further supports the ellipsis view.

\subsubsection{Hindi}

Hindi provides two arguments for the combined ellipsis/movement approach advocated in this paper. The first argument concerns the ellipsis part of the analysis; the second argument reflects the need of an extra scoping mechanism beyond the size of the coordinated constituents (cf. $w h$-movement in English).

Word order in Hindi $y n$ - and alt-questions furnishes the first argument. Hindi being an SOV language, the surface location of the finite verb generally marks the right edge of the clause (and of the VP). This circumstance raises a prediction: if alt-readings are construed by disjoining two IPs (or possibly two VPs) and partially eliding the second IP (or VP) and if no further movement occurs, then the second disjunct should appear after the right boundary of the first IP (or VP). This prediction is borne out. The $y n$ reading of a question such as Did Chandra drink coffee or tea? is expressed by having the NP disjunct coffee or tea in the object position, as in (32). This question can never have an alt-reading.

(Kyaa) Chandra-ne coffee yaa chai pii?

what Chandra-Erg coffee or tea drink-Pfv

'Is it the case that Chandra drank coffee or tea?' (yn-question)

For the alt-reading to obtain, coffee and tea must be separated by the verb drink, as in (33a): coffee is the object of the first disjunctive clause, and tea occurs alone in the second disjunct. As predicted by our analysis, this 
suggests that, in the alt-reading, yaa ('or') coordinates two full clausal constituents, rather than two NPs, in the second one of which the subject and the verb have been elided leaving the object chai ('tea') as the only remnant. This is represented in (33b). ${ }^{3}$

(33)a. (Kyaa) Chandra-ne coffee pii yaa chai?

what Chandra-Erg coffee drink-Pfv or tea

'Which of these two things did Chandra drink: coffee or tea?' (alt question)

a. (Kyaa) Q [Chandra-ne coffee pii] yaa [Chane

what $Q$ Chandra-Erg coffee drink-Pfv or Erg

chai pii]?

tea drink Pfu

Let us now turn to the second argument. Based on the distribution of the wh-element kyaa, we will argue that alt-questions involve a scoping mechanism for whether/Q. Interestingly, this scoping mechanism is the same as the one used to give wider scope to regular $w h$-phrases in $w h$ questions.

To make the argument, note, first, that Hindi is a $w h$-in-situ language with LF $w h$-movement (overtly moved $w h$-phrases are generally assumed to be scrambled), as exemplified in (34) (Dayal 1996).

$$
\begin{aligned}
& \text { Tum-ne us-ko kyaa diyaa? } \\
& \text { you-Erg he-Dat what give-Pfv } \\
& \text { 'What did you give him?' }
\end{aligned}
$$

It has also been noted that LF wh-movement is not possible out of finite clauses in Hindi, as in (35).

(35) Tum jaante ho [ki us-ne kyaa kiyaa $]$ you know be that he-Erg what do-Pfv

'You know what he did.'

*'What do you know he did?'

\footnotetext{
3 In principle, a $y n$-question reading should be available to (33a), as well as an altreading. But only alt-reading seems to be readily available to native speakers. This may be a pragmatic effect caused by disjoining full clauses in a whether/ $Q$ question. The same effect is attested in English whether questions with two disjoined clauses: e.g., I wonder whether John drank coffee or he drank tea. We will see later (cf. (37), (43b)) that a $y n$ question reading is available to whether/Q questions when disjoined clauses are restricted to embedded contexts.
} 
The way to obtain a direct question when the $w h$-phrase originates in an embedded finite clause is by using the wh-element kyaa 'what' in the matrix clause, where it acts as the scoping mechanism for the embedded wh-phrase, as in (36). ${ }^{4}$ Note that the presence of kyaa is obligatory for the embedded $w h$-phrase to attain matrix scope in this example. When there is no such embedding (e.g., in simple alt-questions like (33a) and in simple $y n$-questions like (32)), kyaa is merely optional. ${ }^{5}$

$$
\begin{aligned}
& \text { Jaun kyaa soctaa hai [ki merii kis-se baat karegii]? } \\
& \text { John what think be-Pres that Mary who-Ins talk do-Fut } \\
& \text { 'What does John think, who will Mary talk to?' } \\
& \text { i.e., 'Who does John think Mary will talk to?' }
\end{aligned}
$$

The issue we want to examine here is what happens with Hindi altquestions with disjunction originating from an embedded clause, as in (37). Do we coordinate two matrix clauses allowing for ellipsis to spread across a finite clause boundary, as in (38)? Or, in a way comparable to our hybrid proposal for English, does or coordinate only the two embedded IPs, as in (39), and an extra scoping mechanism is responsible for the matrix scope interpretation of the embedded whether/ $Q$ ?

$$
\begin{aligned}
& \text { Jaun kyaa sochtaa hai [ki Chandra-ne coffee pii } \\
& \text { John what think be-Pres that Chandra-Ern coffee drink-Pfv } \\
& \text { thii yaa chai]? } \\
& \text { Past or tea } \\
& \text { English counterpart: 'Does John think that Chandra drank } \\
& \text { coffee or tea?' (alt-question) }{ }^{6}
\end{aligned}
$$

\footnotetext{
4 According to Dayal $(1996,2000)$, in examples such as (36), both kyaa in the matrix clause and kis-se in the embedded clause are regular wh-phrases, each undergoing LF movement to the [Spec, CP] of their respective clauses. Semantically, kyaa is treated as quantifying over propositions and the embedded clause forms the restriction of this quantification. This semantic mechanism ends up returning as possible answers the "propositions that John stands in the think relation to and which furthermore are members of the indirect question' (Dayal 1996, p. 7). In effect, the set of possible answers are: \{John thinks that Mary will talk to Sue, John thinks that Mary will talk to Sita, John thinks that Mary will talk to Chandra ... \}. Thus, the embedded $w h$-phrase obtains matrix scope interpretation, without actually having matrix scope structurally.

5 Note that while Hindi clauses in general have SOV word order, CP complement clauses occur to the right of the verb.

6 (37) can have either an alt-question reading or a $y n$-question reading. Here we are only concerned with the alt-reading. The alt-reading can be semantically derived equally from the structure in (38) and from the structure in (39).
} 


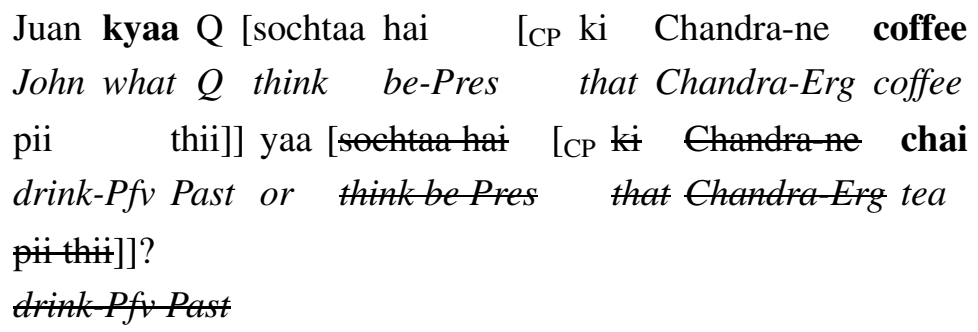

'Which one is true: John thinks that Chandra drank coffee or John thinks that Chandra drank tea?' (same reading as in (39))

(39) Jaun kyaa sochtaa hai [CP Q ki [Chandra-ne coffee John what think be-Pres $Q$ that Chandra-Erg coffee pii thii] yaa [Chandra ne chai pii thiil]?

drink-Pfv Past or tea Pf Past

'Which does John think: that Chandra drank coffee or that Chandra drank tea?' (same reading as in (38))

We argue that the correct structure for the alt-reading of (37) is (39), a hybrid ellipsis/scoping structure, for the reason that kyaa is obligatory for the alt-reading of (37) to obtain and that removing kyaa, as in (40), renders the alt-reading impossible. That is, the matrix $y n$-reading obtains both in (37) and in (40), no matter whether kyaa appears or not, but the alt-reading can only obtain when kyaa is present.

(40) Jaun sochtaa hai [ki Chsnfts-ne coffee pii thii John think be-Pres that Chandra-Erg coffee drink-Pfv Past yaa chai]?

or tea

*Which does John think: that Chandra drank coffee or that he drank tea?' (alt-question)

'Is it the case that John thinks this: that Chandra drank coffee or tea?' (yn-question)

If we were to assume a pure ellipsis account and take the structure in (38), the scope of disjunction would be in the matrix clause already, and, hence, the particle kyaa would be expected to be optional, as it is in (33a) and in the matrix $y n$-question reading of (40). Under the hybrid ellipsis/scoping account with the structure in (39), the need for kyaa here is explained as the need for kyaa with embedded $w h$-phrases. Wh-phrases by themselves cannot take scope beyond their clause, and neither can gapping spread 
across a finite clause, as the examples (41)-(42) with declaratives show. Both with regular wh-phrases and with disjunctive $w h$-phrases, then, the presence of the extra scoping mechanism is necessary in order to give the embedded $w h$-element a matrix scope interpretation.

(41) Sue aaluu pasand kartii hai aur Martha pyaaz.

Sue potatoes like do-Hab be-Pres and Martha onions

'Sue likes potatoes and Martha onions.'

(42) Sue sochtii hai ki mE Bill-ko pasand kartaa huN

Sue think-Hab be-Pres that I Bill-Dat like do-Hab be-1Sg aur Martha Tom-ko

and Martha Tom-Dat

'Sue thinks that I like Bill and Martha (likes) Tom.'

*'Sue thinks that I like Bill and Martha (thinks that I like) Tom.'

In fact, the scoping mechanism for embedded $w h$-phrases and the scoping mechanism for embedded whether/ $Q$ in Hindi not only share the necessary presence of kyaa, but they are also equally subject to island constraints. For instance, (43a) is grammatical under the $y n$-reading, but it is impossible under the matrix $w h$-question reading. Similarly, kyaa cannot mark the scope of whether/ $Q$ associated with a disjunction in an island. That is why (43b) cannot be interpreted as an alt-question. It can only be interpreted as a $y n$-question.

(43)a. Ram-ko kyaa yeh baat pataa hai ki Chandra-ne Ram-Dat what this thing known be-Pres that Chandra-Erg kyaa pii thii? what drink-Pfv Past

'Does Ram know what Chandra drank?'

*'What does Ram know the fact that Chandra drank?'

b. Ram-ko kyaa yeh baat pataa hai ki Madhu-ne chai Ram-Dat what this thing known be-Pres that Madhu-Erg tea pii thii yaa coffee? drink-Pfv Past or coffee

'Does Ram know the fact that Madhu drank tea or Madhu drank coffee?' (yn-question)

*'Which fact does Ram know: that Madhu drank tea or that Madhu drank coffee?' (alt-question) 
In summary, Hindi alt-questions are explained under the combined ellipsis/scoping account. First, word order facts suggest that Hindi altquestions involve ellipsis. Second, given that this type of ellipsis (gapping) cannot spread across a finite clause boundary, a scoping mechanism with obligatory kyaa is needed in order to give matrix scope interpretation to a disjunction originating in an embedded clause. This ellipsis/scoping analysis for Hindi is parallel to the ellipsis/movement analysis we want to propose for English, hence lending crosslinguistic support to it.

\subsubsection{Korean}

Word order and case-marking facts support the ellipsis analysis of altquestions in Korean. As in Hindi, Korean questions with an associated disjunctive phrase such as coffee or tea in the object position can only have a $y n$-question reading, as in (44).

(44) Chelswu-ka khophi-na cha-lul masi-ess-ni?

Chelswu-Nom coffee-or tea-Acc drink-Past-Int

'Is it the case that Chelswu drank coffee or tea?' (yn-question)

In order to obtain an alt-question reading, first of all, a different disjunctive connective, animyen which literally means if not, must be used. In contrast to -na as in (44), animyen can only disjoin clause level constituents, and only has the meaning of exclusivity. Second, coffee must be part of the first disjunctive clause, and tea must be part of the second disjunctive clause. There are two ways to achieve this: (i) by disjoining two clauses (or possibly two VPs) without deleting the verb from either of the clauses (or VPs), as in (45a); or (ii) by disjoining two clauses (or two VPs) with deletion of the verb from the first clause (or first VP), as in (45b).

(45)a. Chelswu-ka khophi-lul masi-ess-ni animyen cha-lul

Chelswu-Nom coffee-Acc drink-Past-Int if-not tea-Acc masi-ess-ni?

drink-Past-Int

'Which of these two things did Chelswu drink: coffee or tea?' (alt-question)

b. Chelswu-ka khophi-lul animyen cha-lul masi-ess-ni?

Chelswu-Nom coffee-Acc if-not tea-Acc drink-Past-Int

'Which of these two things did Chelswu drink: coffee or tea?' (alt-question) 
The syntax of (45a) as a disjunction of two clauses is straightforward. Korean, however, is different from Hindi and English in that deletion targets the verb in the first clause and not the one in the second clause, as the contrast between (45b)-(46) shows. This deletion pattern is the same that we encounter in gapping in Korean declaratives, as in (47a) and (47b):

(46) *Chelswu-ka khophi-lul masi-ess-ni animyen cha-lul?

Chelswu-Nom coffee-Acc drink-Past-Int in-not tea-Acc

'Which of these two things did Chelswu drink: coffee or tea?' (alt-question)

(47)a. Tol-i Seoul-ey kuliko Anoop-i India-ey sal-ass-ta.

Tol-Nom Seoul-in and Anoop-Nom India-in live-Past-Decl

'Tol lived in Seoul and Anoo in India.'

b. ${ }^{*}$ Toi-i Seoul-ey sal-ass-ko kuliko Anoop-i India-ey.

Tol-Nom Seoul-in live-Past-Conj and Anoop-Nom India-in

'Tol lived in Seoul and Anoop in India.'

One may think that the surface string of (45b) illustrates ellipsis from an unbalanced disjunction, as represented in (48).

(48) [Chelswu-ka khophi-lul masies ni] animyen [cha-lul

Chelswu-Nom cpffee-Acc drink PastInt if-not tea-Acc

masi-ess-ni]?

drink-Past-Int

'Which of these two things did Chelswu drink: coffee or tea?' (alt-question)

But (45b) has two other possible structural analyses available that do not involve ellipsis from an unbalanced disjunction. One is where the subject in the second clause is pro, ${ }^{6}$ and the other is an analysis with VP disjunction/coordination. Each of these possibilities is represented in (49) below.

${ }^{6}$ Like Japanese and Chinese, Korean is a pro-drop language. 
(49)a. [Chelswu-ka khophi-lul ni] animyen [pro cha-lul Chelswu-Nom coffee-Acc Pro tea-Acc masi-ess-ni]?

drink-Past-Int

'Which of these two things did Chelswu drink: coffee or tea?' (alt-question)

b. Chelswu-ka [khophi-lul asiess ni] animyen [cha-lul

Chelswu-Nom coffee-Acc tea-Acc masi-ess-ni]?

drink-Past-Int

'Which of these two things did Chelswu drink: coffee or tea?' (alt-question)

Let us now turn to case marking in Korean, which also provides evidence for the ellipsis analysis of alt-questions. In the alt-question (45b), the occurrence of the accusative case marker in both khophi-lul ('coffee') and cha-lul ('tea') suggests that clause disjunction is involved here rather than a simple noun phrase disjunction. As shown in the yn-question (44), a simple noun phrase disjunction allows case marking only on the head noun (i.e., the noun at the right edge of the NP). An example with a simple noun phrase conjunction also allows case marking only on the head noun, as in (50).

(50) John-i Mary-wa Sue-lul po-ass-ta.

John-Nom Mary-and Sue-Acc see-Past-Decl

'John saw Mary and Sue.'

Moreover, in (45b), each accusative-case marked noun can be followed by an adverb as illustrated in (51a), supporting our claim that it involves clause disjunction with verb deletion in the first clause. On the other hand, this is impossible in (44), illustrated in (51b), as we would expect for a simple noun phrase disjunction.

(51)a. Chelswu-ka khophi-lul ppali animyen cha-lul ppali

Chelswu-Nom coffee-Acc quickly if-not tea-Acc quickly masi-ess-ni?

drink-Past-Int

'Which of these two things did Chelswu drink quickly: coffee or tea?' (alt-question) 

b. ${ }^{*}$ Chelswu-ka khophi-na ppali cha-lul ppali
Chelswu-Nom coffee-or quickly tea-Acc quickly
masi-ess-ni?
drink-Past-Int

'Is it the case that Chelswu drank coffee or tea quickly?' (ynquestion)

Further, the case-marking facts attested in alt-questions is similar to the way case marking works in gapping in declaratives, supporting our claim that alt-questions and gapping have similar syntax. (52a) is an example of gapping in a declarative sentence, where the verb in the first conjunct has been deleted, as represented in (52b). The case marking in the first conjunct with verb deletion is the same as the second conjunct without the verb deletion: i.e., in both conjuncts, the subject NPs must bear nominative case markers and the object NPs must bear accusative case markers. A parallel example of alt-question is given in (53).

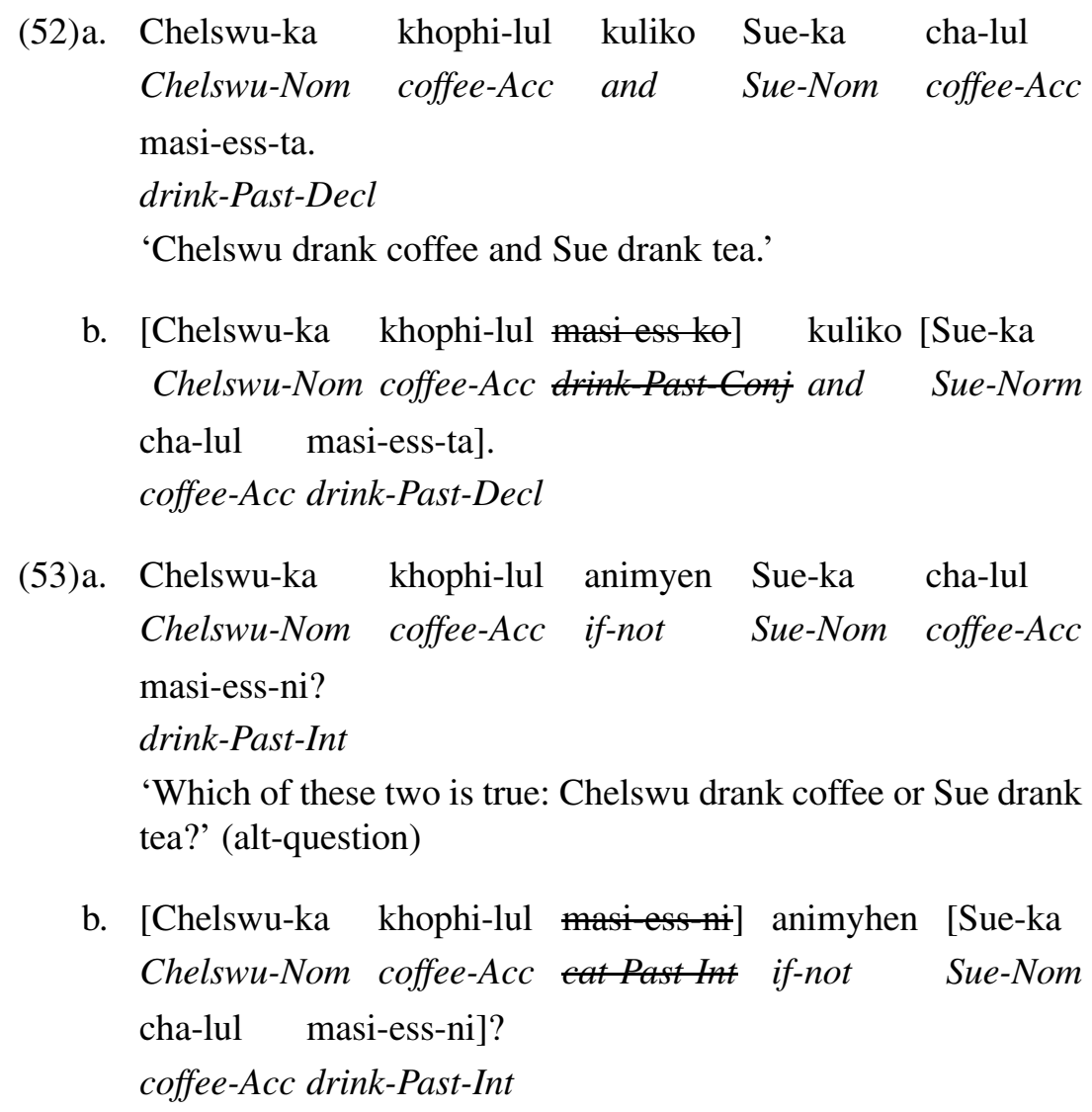


In sum, the data on word order and case marking in Korean show that alt-questions must disjoin full clauses (or VPs), and not just two NPs. This provides an indirect support for ellipsis in the syntax of English alt-questions.

\subsection{Focus Pattern in English}

The question now is whether English has any independent evidence for ellipsis in the syntax of alt-questions. In this subsection, we argue that a suggestive piece of evidence comes from the focus pattern found in altquestions.

A (written) question such as Did John drink coffee or tea? has, in principle, two potential readings: the $y n$-question reading and the alt-question reading. However, as noted in Romero (1998), focus intonation disambiguates the two readings: the $y n$-reading presents neutral intonation on the disjunctive phrase, as in (54a), whereas the alt-reading is in general achieved by placing focus stress on each disjunct, as in (54b).

(54)a. Did John drink coffee or tea? (neutral intonation, yn-reading only)

b. Did John drink COFfee or TEA? (focus in capitals, alt-reading only)

In a question with gapping in the second clause, as in (55), the remnant and the correlate are focused and the question only has the alt-reading.

Did JOHN drink COFfee or MARY TEA?

Also, a $y n$-reading in a question with overt or not correlates with the presence of stress on the verb and on not, as in (56).

\section{Did John DRINK or NOT?}

What is the function of this double focus? A common use of focal stress is to signal that the sentence with the focus is semantically parallel to some other nearby sentence, contrasting only in the focused part. ${ }^{8}$ For example, in (57), the two disjunctive clauses are parallel to each other, differing only in the content of the NP objects. Similarly, in (58), the two adjacent clauses naturally bear stress on the non-common elements, namely on the contrastive NP subjects and on the contrastive temporal adjuncts. Finally,

\footnotetext{
${ }^{8}$ For a formalization of the felicity conditions of contrastive focus, see Rooth (1985, 1992).
} 
the same holds for (59), where the polarities and the embedded predicates differ from each other and bear focal stress:

(57) Either [IP Sita ate BEEF for dinner] or [IP she ate PORK for dinner].

(58) [IP PAT visited Sue for CHRISTmas], and [IP JOHN visited Sue for NEW YEAR].

(59) [IP Noa does NOT play tennis when the ground is WET]. [IP She PLAYS it when the ground is DRY].

In cases where disjoined sentences involve ellipsis in the second clause, the remnant material must necessarily bear some focal stress. This necessary focus on the remnant is typically mirrored with focus stress on the correlate, since the remnant and its correlate are the parts that are contrasting with each other.

(60)a. MaTILda WENT to the theatre, but SUsan did NOT so the ther.

b. JOHN drank COFfe and MARY drank TEA.

We can now see that a similar analysis can be applied to whether/Q ...or constructions, naturally explaining the double focus, if they also involve disjunction of clauses, and in some cases ellipsis in the second clause. For instance, in (61b), each of the constituents in IP1 contrasts with the corresponding constituent in IP2, hence focus stress is placed on all of them. ${ }^{9}$

(61)a. Did MARY SING or BILL DANce?

b. $Q_{i}$ Did $t_{i}$ [IP1 MARY SING] or [IP2 BILL DANce]?

Further, if whether $Q$... or constructions are clausal disjunctions, then the examples in (54b) and (56), as well as the example in (55), all involve ellipsis in the second clause. The resulting structures are illustrated in (62). For these examples, the focus stress falls on the remnant and its correlate,

\footnotetext{
9 We thank a reviewer for raising the issue of focus pattern in alt-questions that do not involve ellipsis, and for pointing us to relevant examples.
} 
as is typical in elliptical constructions like VP-ellipsis (as in (60a)) and gapping in declaratives (as in (60b)).

(62)a. $Q_{i} \operatorname{Did} t_{i}\left[{ }_{I P}\right.$ John drink COFfee] or [IP drink TEA]?

b. $Q_{i} \operatorname{Did} t_{i}\left[{ }_{I P}\right.$ John DRINK] or [ ${ }_{I P}$ he NOT drink $]$ ?

c. $Q_{i}$ Did $t_{i}\left[{ }_{I P}\right.$ JOHN drink COFfee $]$ or $\left[{ }_{I P}\right.$ MARY drink TEA $]$ ?

Under the movement-only analysis, there is no straightforward way to account for the difference in the focus pattern between the $y n$ - and the alt-reading. For instance, the example in (14) (repeated here as (63)), has two possible derivations under the movement-only analysis, depending on whether it has the $y n$ - or the alt-reading.

(63) Did John drink coffee or tea?

a. $y n$-question:

$\mathrm{Op}_{i}\left(t_{i}\right.$ or not) [did John drink [Op ${ }_{j}$ coffee or tea]]

b. alt-question:

$\mathrm{Op}_{i}$ [did John drink $\left[t_{i}\right.$ COFfee or TEA] $]$

In both derivations, coffee or tea is associated with an operator. The difference is that in the alt-reading, the operator associated with it moves to COMP, while in the $y n$-reading, it does not move. It is not clear how we can link the $y n$-reading configuration to no accent and the alt-reading configuration to the double accent focus pattern.

The same point can be raised for either ... or constructions. According to the native speakers that we consulted, while clausal either ... or in $(64 \mathrm{~b}$, c) necessarily triggers double focus on the disjuncts, either NP or NP in (64a) doesn't necessarily do so. ${ }^{10}$

(64)a. John drank either coffee or tea.

b. Either John drank COFfee or TEA.

c. John either drank COFfee or TEA.

To further verify this intuition, consider the context in (65). Although the judgments are subtle, all the native speakers we consulted agreed that

\footnotetext{
10 For some speakers, it was possible to put double focus on the disjuncts in (64a) in some contexts, although not as strong as in $(64 \mathrm{~b}, \mathrm{c})$. The crucial point for us is that while sentences with either placed at VP or at IP level necessarily carry double focus on the disjuncts, those with either placed at the NP level do not necessarily do so.
} 
while (65a) is a perfect continuation, (65b) is funny. Note that the scenario is set up in such a way that the constituents being contrasted are drank and ate, and not coffee and tea. This means that while drank and ate must be stressed, coffee and tea should not be. This intonational pattern is compatible with (65a) because the NP disjunction coffee or tea in (65a) does not necessarily have double focus. However, in (65b), coffee or tea necessarily has double focus - since it involves clausal disjunction plus ellipsis -, which is in conflict with the intonational pattern called for by the context.

(65) CONTEXT: John is discovered dead in his office 15 minutes after the lunch he attended is over. He's been poisoned. The police suspects that the poison was in the food and they are trying to find out what he ate. Then A says:

a. A: John drank either coffee or tea, but I've no idea what he ate.

b. \#A: John either drank coffee or tea, but I've no idea what he ate.

In sum, nothing in the movement-only analysis per se predicts an intonational difference between disjunction that moves to a clausal site (movement analysis for (63b) and $(64 \mathrm{~b}, \mathrm{c})$ ) and disjunction that remains at the NP level (examples (63a) and (64a)). Under the ellipsis analysis, instead, the necessary double focus on the disjuncts in (63b) and (64b, c) can be explained as the focus that signals the necessary contrast between a remnant and its correlate in ellipsis. Focal stress in (63a) and (64a) is optional and is probably determined by discourse factors, depending on whether or not the disjuncts are meant to be used contrastively in that context.

\subsection{Summary of Section 5}

We started this section by pointing out that, once whether/Q $\ldots$ or is recognized as the $w h$-version of either ...or, and given that coordination is crosscategorial and gapping is available in the grammar, an alt-question like (66) can in principle have the derivations in (66a) and in (66b). The question was: does one of the two derivations win over the other and, if so, which one?

(66) Did John drink coffee or tea?

a. $Q_{i}$ Did John drink $t_{i}$ [coffee or tea]

b. $Q_{i}$ Did $t_{i}$ [John drink coffee or trink tea] 
We have seen that the string syntax of Hindi and Korean alt-questions can only be explained if the derivation of the alt-reading involves disjunction of two clausal nodes, as in (66b), and not coordination of two NPs, as in (66a). That is, the crosslinguistic data show that the ellipsis/movement derivation in (66b) must win over the pure movement derivation in (66a). Data on the phonological focus pattern of whether/Q ... or constructions in English also suggest that these questions must also be derived via ellipsis plus movement. In view of these data, we conclude that whether/Q ... or constructions are the $w h$-version of clausal either ...or constructions, hence involving both ellipsis and movement.

A question still remains as to why in alt-questions the derivation involving clausal disjunction with ellipsis wins over the pure movement derivation. We do not have a full answer to this question. However, note that for an alt-question like (66) the movement in the combined movement/ellipsis derivation in (66b) is shorter than the one in the movementonly derivation in (66a). An economy principle preferring Shortest Move may point us towards an answer: it may be that, for a given reading, shorter movement from disjunction of larger constituents (with consequent ellipsis) is preferred over longer movement from disjunction of smaller constituents.

\section{Combination of Ellipsis and Movement in Alternative QUESTIONS}

Incorporating insights from both Larson and Schwarz, we have so far argued that the syntax of whether/Q ... or constructions like (1) and (3) involves disjunction of clauses with consequent ellipsis in the second clause, as well as movement of whether/ $Q$ associated with a disjunctive clause to the matrix [Spec, CP]. In this section, we will first show how our combined movement/ellipsis analysis handles the apparent asymmetries between either ... or and whether/Q ...or discussed in section 3. We will then briefly consider possible analyses of $y n$-questions without an overt associated disjunction.

\subsection{Asymmetries between either ... or and whether/Q ... or}

Recall from section 3 that while either ... or constructions do not allow dangling remnants and ellipsis across finite clauses, whether/Q ...or constructions seem to do so. The examples illustrating these apparent 
asymmetries are given in (67)-(69), with the corresponding derivations under a pure ellipsis account.

(67)a.??Either this pissed Bill or Sue off.

Either [IP this pissed Bill] or [IP his Sue off]

b. Did this piss Bill or Sue off?

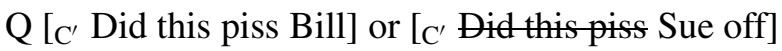

(68)a.??Either John said that Bill retired or resigned.

Either [IP John said that Bill retired] or

[IP

b. Did John say that Bill retired or resigned?

Q [C ${ }^{\prime}$ Did John say that Bill retired] or

[C' ${ }^{\prime}$ id John Bill resigned]

(69)a.??Either John claimed that Bill drank coffee or tea.

Either [IP John claimed that Bill drank coffee] or

[IP Billetamat tea]

b. Did John claim that Bill drank coffee or tea?

Q [C ${ }^{\prime}$ Did John claim that Bill drank coffee] or

[IP Did Bill claim that John drank tea]

The starting point of our analysis is that the degraded either ... or constructions with a dangling remnant and those with ellipsis spreading across matrix and finite embedded clauses become well-formed if either is lower in the clause.

(70)a. This either pissed Bill or Sue off.

b. This either [vp pissed Bill $e_{j}$ ] or [vp Sue $e_{j}$ ] off ${ }_{j}$

(71)a. John said that Bill either retired or resigned.

b. John said that Bill either [vp retired] or [vp resigned]

(72)a. John claimed that either Bill drank coffee or tea.

b. John said that either [IP Bill drank coffee] or [IP Billdrank tea] 
According to Schwarz, in (70a), either is adjoined to VP marking the left periphery of the first disjunct, and the particle off has undergone right-node raising, as represented in (70b). Given this analysis, the only elided material is the verb pissed in the second disjunct, and so there is no dangling remnant. Schwarz further notes that in (67a) (repeated here as (73a)) the option of right-node raising the particle, as in (73b), is difficult, if not completely unavailable, because the particle would have to right-node raise above IP. But the right-node raising option is available for (70a) because the particle is required to raise only above VP.

(73)a.??Either this pissed Bill or Sue off.

b.??Either [IP this pissed Bill $e_{j}$ ] or [IP this pissed Sue $e_{j}$ ] off $j$.

In (71a), either is adjoined to the embedded disjunctive VP, and so there is no ellipsis involved, as represented in (71b). In (72a), either is adjoined to the embedded disjunctive IP, with ellipsis in the second IP. Both sentences are well-formed with the reading in which the scope of or is restricted to the embedded clause.

The difference between whether/ $Q$ and either is that whether/ $Q$ is a wh-phrase, while either is not, and so whether/ $Q$ can undergo movement, leaving a trace, while either cannot. In other words, the trace of whether/Q corresponds to the surface position of either. This means that while either marks the left edge of the disjunction in either ... or constructions, the trace of whether/Q marks the left edge of disjunction in whether/Q ... or constructions. This in turn means that the left edge of ellipsis can be the originating position of whether/Q, and not its surface position, and that as long as there is a grammatical source sentence with either, the corresponding whether/Q sentence should be well-formed. Further, the movement of whether/Q to matrix [Spec, CP] will expand the scope of or, allowing it to have the widest scope. This then is why whether/Q $\ldots$ or constructions appear to allow dangling remnants and ellipsis across matrix and embedded finite clauses. The LFs we propose for (67b)-(69b) are given in (74a)(74c) respectively. For us, (67b) does not involve a dangling remnant, and (68b)-(69b) do not involve ellipsis across matrix and finite embedded clauses.

(74)a. $Q_{i}$ Did this $t_{i}$ [vp piss Bill $e_{j}$ ] or [vp piss Sue $e_{j}$ ] off ${ }_{j}$

b. $Q_{i}$ Did John say that Bill $t_{i}$ [vP retired] or [vp resigned]

c. $Q_{i}$ Did John claim that $t_{i}$ [IP Bill drank coffee] or [IP Billdrank tea] 
In our analysis, the apparent ellipsis from unbalanced disjunction actually involves disjunction of VPs with ellipsis in the second VP and a right-node raised particle. The apparent ellipsis across matrix and embedded finite clauses also involves disjunction of VPs or IPs. Further, in this case, the movement of $Q$ to matrix [Spec, CP] allows or to have the widest scope, giving rise to the alt-reading.

Two questions concerning the contrast between (70a) and (73a) (repeated below as (75a) and (75b)) need to be addressed at this point. ${ }^{11}$

(75)a.??Either this pissed Bill or Sue off.

b. This either pissed Bill or Sue off.

First, is there an alternative non-ellipsis account of the contrast in (75) that makes the same prediction as Schwarz's gapping and right-node raising analysis? A reviewer suggests that an alternative analysis may be possible if the strategy proposed in Kayne (1998) for the syntactic derivation of negative sentences like (76) is adopted.

(76) I forced us to turn no one down.

In (76), no one cannot have wide scope. According to Kayne, the derivation that obtains wide scope reading of no one would involve movement of no one to $[\mathrm{Spec}, \mathrm{NegP}]$ in the matrix clause, followed by particle raising and remnant VP movement, as in (77). But the problem is that the particle would have to raise out of the embedded clause and undergo a longdistance movement to the matrix clause. For Kayne, this is illegal, and hence (76) cannot be associated with a wide scope reading of no one.

(77) Source: I forced us [to turn no one down].

a. Neg preposing:

I no one ${ }_{i}$ forced us [to turn $t_{i}$ down]

b. Particle preposing: *

I no one ${ }_{i}$ down $_{k}$ forced us [to turn $t_{i} t_{k}$ ]

c. Remnant VP movement:

I [vP forced us to turn $\left.t_{i} t_{k}\right]_{j}$ no one $_{i}$ down $_{k} t_{j}$

In a nutshell, if we were to apply Kaynean strategy to the examples in (75), the derivations would involve particle raising and either NP or

11 We thank the reviewers for raising these important questions. 
$N P$ raising, followed by a remnant VP/IP movement. The derivations for (75a) and (75b) will roughly proceed as in (78) and (79) respectively. The asymmetry in the grammaticality between (75a) and (75b) can then be attributed to the difference in the height of the particle raising: in (75a), the particle raises above IP as in (78a), while in (75b), it raises above VP as in (79a).

(78) Source: [IP this [vp pissed either [Bill or Sue] off]]

a. Particle preposing: ??

off $_{i}$ [IP this pissed either Bill or Sue $t_{i}$ ]

b. Disjunctive NP movement:

[either Bill or Sue $]_{j}$ off $_{i}\left[\right.$ IP this pissed $t_{j} t_{i}$ ]

c. Remnant IP movement:

either [IP this pissed $\left.t_{j} t_{i}\right]_{k}[\text { Bill or Sue }]_{j}$ off $_{i} t_{k}$

(79) Source: this [vp pissed either [Bill or Sue] off]

a. Particle preposing:

this off $i_{i}$ [vp pissed either Bill or Sue $t_{i}$ ]

b. Disjunctive NP movement:

this [either Bill or Sue $]_{j}$ off $_{i}$ [vP pissed $t_{j} t_{i}$ ]

c. Remnant VP movement:

this either [vp pissed $\left.t_{j} t_{i}\right]_{k}[\text { Bill or Sue }]_{j}$ off $_{i} t_{k}$

Note however that in order to derive the correct string order, we are forced to insert the remnant VP/IP in between either and NP or NP. It is not clear to us what kind of syntactic operation would motivate this. Further, the Kaynean strategy cannot be extended to Hindi and Korean. This is because the disjuncts in Hindi and Korean alt-questions do not form contiguous constituents. Admittedly, more thorough research needs to be done to gain full understanding of what all this means. We leave this open for future research.

The second question is concerned with the unmovability of clausal either. It is crucial for Schwarz's analysis that clausal either does not move, for otherwise (80a) could have the parse in (80b) and, since the particle only raises to VP, (80a) would have the same grammaticality status as (81a) (and as (82a)), contrary to fact. ${ }^{12}$

\footnotetext{
12 A reviewer notes that for some speakers, the example in (80a) is somewhat ok, with emphasis, in certain discourse contexts, and suggests that this example cast doubt on the
} 
(80)a.??Either this pissed Bill or Sue off.

b. Either $i_{i}$ this $t_{i}$ [vp piss Bill $e_{j}$ ] or [vp piss Sue $e_{j}$ ] off ${ }_{j}$

(81)a. This either pissed Bill or Sue off.

b. This either ${ }_{i}$ [vp piss Bill $e_{j}$ ] or [vp piss Sue $e_{j}$ ] off ${ }_{j}$

(82)a. Did this piss Bill or Sue off?

b. $Q_{i}$ did this $t_{i}$ [vp piss Bill $e_{j}$ ] or [vp piss Sue $e_{j}$ ] off ${ }_{j}$

The question then arises why clausal either does not move, if after all it is a scopal element. Possibly, IP/VP-adjoined either does not move overtly or covertly - because of its syntactic status as an adjunct. It is generally believed that adverbs do not move. In this sense, the pair formed by either ...or and whether/Q ...or can be compared, e.g., to the pair formed by often and how often. The declarative member of each pair takes surface scope and does not move, whereas the interrogative member of the pair contains a wh-element that must move to [Spec, CP]. That the unmovability of clausal either is somehow due to its status as an adjunct is suggested by two facts. First, as observed in Larson (1985, p. 221), clausal either always takes surface scope, whereas NP disjunction in either NP or $N P$ can move covertly and take wider scope. This is illustrated in Larson's examples (83): clausal either in (83a) cannot have the matrix scope reading paraphrased in (83c), but NP either in (83b) can. This suggests that unmovability is not a characteristic of either per se, but of clausal either.

(83)a. Sherlock pretended [to either be looking for a burglar or a thief].

b. Sherlock pretended [to be looking for either a burglar or a thief].

c. Matrix scope disjunction reading: "One of these is true: Sherlock pretended to be looking for a burglar, or he pretended to be looking for a thief."

Second, independently of disjunction, the same scopal pattern obtains for only: clausal only in (84a) cannot have the matrix reading in (84c), but unmovability of clausal either. But what is important for us is that there is still a contrast in the degree of acceptability between (80a) and (81a)-(82a). For us, this contrast can be attributed to the degree of right-node raising of the particle. We can say that (80a) has right-node raising of a particle above IP, which is only available to some speakers, with difficulty. In contrast, the examples (81a) and (82a) have right node raising above VP, which is readily available to all speakers. If, however, both (80a) and (81a)-(82a) are derived from VP disjunction through movement of either or whether/Q, we would not expect to see any grammaticality contrast between these examples. 
NP only in (84b) can. This suggests that unmovability is not just an idiosyncrasy of clausal either, but a property shared by other particles when functioning as an IP/VP adjuncts.

(84)a. John asked you [to only meet MARY].

b. John asked you [to meet only MARY].

c. Matrix scope reading of only: "John asked you to meet Mary and there is nobody else that John asked you to meet."

\subsection{Syntax of yn-Questions without an Overt Associated Disjunction}

Under our combined movement/ellipsis analysis, the syntax of altquestions and $y n$-questions with overt or not are parallel: both involve ellipsis and a focused remnant, and the semantic difference derives from the different material in the disjuncts. As for $y n$-questions without overt or not, the two following analyses are compatible with the main claims of the present paper.

A first possible approach is that $y n$-questions like (85) are actually a disjunction of affirmative and negative clauses, where $Q$ is associated with or that disjoins the two clauses. Under this approach, one of the clauses has been deleted, including the disjunctive marker $o r$. This is represented in (86).

(85) Did John eat beans or rice?

"Is it the case that John ate any of these two things: beans or rice?"

$Q_{i} \operatorname{did} t_{i}$ [John eat beans or rice]

or [John ar rice]?

A second possible approach is that a $y n$-question does not contain a disjunction of clauses at the level of syntax and so $Q$ does not associate with $o r$, as represented in (87).

(87) Q [Did John eat beans or rice]?

Under this approach, there is no ellipsis in the syntax of $y n$-questions, and the disjunction of affirmative and negative propositions are provided in the semantics (cf. Karttunen 1977). ${ }^{13}$

\footnotetext{
13 As pointed out in Ladusaw (1980) and Higginbotham (1993), alt-questions do not license NPIs, while $y n$-questions do. For instance, while (ia) is ambiguous between a $y n$ question and an alt-question, (ib) can only be interpreted as a $y n$-question.
} 
To sum up section 6 , the asymmetries between whether/Q $\ldots$ or and either ... or constructions in English are resolved once we realize that whether/Q is a $w h$-element and that, as such, it is subject to $w h$-movement. This leaves clear the way for a unified account of the two constructions, as we have proposed in this paper: the structure of whether $/ Q \ldots$ or questions is the result of adding $w h$-movement to the structure of either VP/IP or VP/IP declaratives, where the second disjunct is (possibly) partially elided. This analysis is compatible with two main different approaches to $y n$-questions without associated overt or not: the negative alternative is provided by an elliptical second disjunct in the syntax, or it is directly provided in the semantics. ${ }^{14}$

(i)a. Did John play chess or checkers?

b. Did anyone play chess or checkers?

Our syntax of $y n$ - and alt-questions does not make any predictions with respect to NPI licensing. Under our analysis, (ib) would be represented as (ii) for the $y n$-reading and as (iii) for the alt-reading. As far as syntax is concerned, if an NPI is licensed in the structures in (ii) (possibly because it is in the c-command domain of $Q$ ), it should also be licensed in (iii) as well. NPIs in an alt-question cannot be ruled out by the double focus on the remnant and the correlate either, since contrastive focus in ellipsis, by itself, does not block NPI licensing, as the VP-ellipsis example (iv) shows:

(ii)a. Possibility 1:

$Q_{i}$ did $t_{i}$ [anyone play chess or checkers]

or o

b. Possibility 2:

$\mathrm{Q}$ [did anyone play chess or checkers]

(iii) $Q_{i} \operatorname{did} t_{i}$ [anyone play chess] or [anyone play checkers]

(iv)a. Neither did JOHN visit anybody nor did MAry.

b. Neither did JOHN visit anybody nor did MAry wisit anybedy.

The ungrammaticality of NPIs in alt-questions can be explained if NPI licensing in questions applies at a level more abstract than LF, along the lines proposed in Higginbotham (1993) and Han and Siegel (1997). A reviewer points out that perhaps the alt-reading of (ib) can be ruled out for the same reason as the following paraphrase is ill-formed: "Was it chess that anyone played or was it checkers that anyone played?" While we agree that both cases may be ruled out under the same semantic account (e.g., the presupposition that one of the choices is true clashes with NPI-licensing), we saw in (iv) that the contrastive focus we have argued for in alt-questions does not prevent NPI-licensing in other ellipsis constructions.

14 A reviewer points out the interesting fact that disjunction of two clauses headed with whether, as in (i), yields only the alt-reading and not the $y n$-reading. We note that the same 


\section{ElLipsis in CONJUNCTION With Right-Node RAISING}

So far, we have considered whether/Q ... or constructions that have a VP disjunctive phrase or a disjunctive phrase in an object position. How then should we handle constructions with disjunctive phrase in other positions? Here, we will consider three such cases: (i) alt-questions with disjunction in a subject position; (ii) alt-questions with a verb disjunction; and (iii) constructions in which the disjunction phrase is whether or not.

An account consistent with our approach for alt-questions, and also used in Schwarz's account of either ... or (see (70b)), is to postulate that some material undergoes right-node raising. In an example with disjunction in subject position, as in (88), the VP finish the paper right-node raises, making available the two alternatives Mary finished the paper and John finished the paper. This can be represented as in (89). ${ }^{15}$

Did Mary or John finish the paper?

$$
\text { Did [IP Mary } \left.e_{i} \text { ] or [IP John } e_{i} \text { ] [VP finish the paper }\right]_{i} ?
$$

For alt-questions with verb disjunction, as in (90), we can also argue that the object NP the book has undergone right-node raising, making

alt-interpretation obtains when we have two separate direct questions conjoined with or, as in (ii). Although this phenomenon is beyond the scope of this paper, we would like to suggest that the reinterpretation of two separate $y n$-questions as one single alt-question is probably a pragmatic effect: in the same way that a wh-question like Which student came? can be broken into a family of yn-questions \{ "Did John come?", "Did Sue come?", "Did Bill come?" ... , an alt-question is pragmatically a family of $y n$-questions containing only two subquestions. Hence, it is not strange that listing the members of that family gives rise to the same pragmatic partitioning of the background set of worlds as the regular altquestion does. (See, e.g., Roberts (1996) on families of questions and see Groenendijk and Stokhof (1984) on partitioning and the pragmatics of questions/answers.)

(i) I wonder whether he's drunk or whether he's just tired. Is he drunk? Or is he just tired?

15 There are two main approaches to the syntax of right-node raising. One approach takes right-node raising to be rightward across-the-board movement (Ross 1967; Bresnan 1974; Postal 1974; Williams 1981), as schematically represented in (ia). The movement approach has been found to be problematic, the most obvious reason being that a constituent can right-node raise out of islands. Another approach takes the right-node raised constituent to be part of a discontinuous structure (McCawley 1982; Levine 1985). This is schematically represented in (ib). In this approach, the constituent shared by the coordinate structure is simultaneously contained in all of its associated conjuncts. 
available the alternatives Mary bought the book and Mary borrowed the book, as represented in (91). ${ }^{16}$

(i)

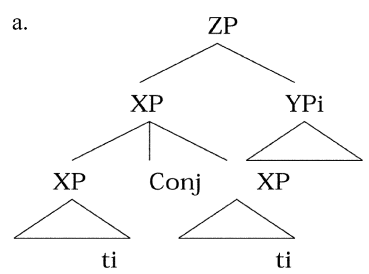

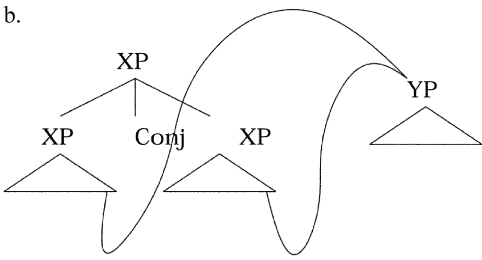

Whatever the correct analysis may be, the important point for us is that both approaches presuppose that right-node raising involves coordination at a clausal level. In representing right-node raising in this paper, for the sake of convenience and simplicity, we will place the right-node raised constituent to the right of the disjunctive clause, and $e$ in each disjunct where the raised constituent is interpreted.

16 A reviewer points out that our remark about Hindi that a sentence of the form (ia) below (as in (32)) cannot be understood as an alt-question presupposes that either rightnode-raising of the verb in (ib) is impossible in Hindi or that Hindi has right-node raising but such a parse cannot give rise to an alt-reading. S/he then provides the example in (ii), as a case of right-node raising, and reports that it can only have the $y n$-reading.

$$
\begin{aligned}
\text { (i)a. } & \text { Subj Obj or Obj Verb } \\
\text { b. } & \text { [Subj [ Obj } \left.\left.e_{i} \text { or Obj } e_{i}\right] \operatorname{Verb}_{i}\right]
\end{aligned}
$$

(ii) Kyaa Ram-ne beans yaa Sitaa-ne aalu khaa-e? what Ram-Erg beans-Fem or Sita-Erg potatoes-Masc-Pl eat-Pfv-Masc-Pl

'Did Ram eat beans or Sita eat potatoes?'

According to the native speakers of Hindi that we consulted with, although it is quite hard to get the alt-reading for (ii), it is not impossible if yaa is stressed and the verb is destressed. Further, it was pointed out to us that a slightly modified example in (iii) allows for the alt-reading much more easily.

$$
\begin{aligned}
& \text { Kyaa Ram-ne ek kelaa yaa Sita-ne ek aalu khaa-yaa? } \\
& \text { what Ram-Erg one banana or Sita-Erg one potato eat-Pfv-Masc-Sg }
\end{aligned}
$$

'Did Ram eat one banana or Sita eat one potato?'

This suggests that, as the reviewer points out, Hindi has right-node raising, but in contrast to what the reviewer says, right-node raising order allows for the alt-reading. This is as we would expect. The question now however is then why our example in (32) that has the form in (ia) does not allow alt-reading if right-node raising parse is in principle possible. It may be that a right-node raising analysis is only available as a last resort and is blocked by the NP disjunctive parse (Rajesh Bhatt, p.c.). A supporting argument that this might be 
(90) Did Mary buy or borrow the book?

(91) Did Mary [vP buy $e_{i}$ ] or [vp borrow $\left.e_{i}\right]$ [NP the book $]_{i}$ ?

Our right node raising analysis can apply to parallel examples from either ...or constructions. This means that examples like (92) and (93) can in principle have two parses: one with simple NP/V disjunction, and another with right-node raising and IP/VP disjunction. For (92), (92a) represents simple NP disjunction parse, and (92b) represents the parse in which the VP finished the paper has undergone right-node raising. For (93), (93a) represents a simple verb disjunction parse, and (93b) represents a parse in which the object NP the book has undergone right-node raising.

(92) Either Mary or John finished the paper.

a. [Either [NP Mary or John]] finished the paper.

b. Either [IP Mary $e_{i}$ ] or [IP John $e_{i}$ ] [vP finished the paper $]_{i}$.

(93) Mary either bought or borrowed the book.

a. Mary [either [v bought or borrowed]] the book.

b. Mary either [vp bought $e_{i}$ ] or [vp borrowed $e_{i}$ ] [NP the book $]_{i}$

The ambiguity in parsing for examples such as (92)-(93) can be resolved through focus patterns. While the parse with simple NP/V disjunction is associated with a neutral focus on the disjuncts, the right-node raising parse is associated with double focus on the disjuncts. ${ }^{17}$

In addition, our analysis makes correct predictions with respect to examples such as (94a). Under our analysis, either in (94a) is clausal, and hence (94a) only has the right-node-raising parse as in (94b). It thus is

on the right track comes from the fact that (iv) has an alt-reading, which is similar to (32), but with adverbs that block an NP disjunction parse:

(iv)
(Kyaa) Chandra kal coffee yaa parsoN
chai piyegaa?
what Chandra tomorrow coffee or day-after-tomorrow tea drink-Fut
'Will Chandra drink coffee tomorrow or will he drink tea a day after tomorrow?'

17 A reviewer points out that according to Neijt (1979, pp. 3-4), either cannot disjoin lexical categories. If so, the only possible parse for examples like (93) is the right-node raising parse. 
degraded for the same reason that (67a) is degraded: material from within VP has undergone right-node raising above IP. ${ }^{18}$

(94)a. ?Either Mary bought or borrowed the book.

b. Either [ $I_{P}$ Mary bought $\left.e_{i}\right]$ or $\left[{ }_{I P}\right.$ Mary borrowed $\left.e_{i}\right]$ [NP the book $]_{i}$

For constructions in which the disjunction phrase is whether or not, as in (95), a possible analysis is the following. The source sentence is represented as in (96a). Then, raising the positive (POS) and negative polarities, or reconstructing the subjects to [Spec, VP], yields the constituency structure in (96b). Finally, the entire clause John finished the paper right-node raises out of both disjuncts, as represented in (96c).

(95) I don't know whether or not John finished the paper.

(96)a. ... whether [IP John finished the paper] or [IP John did not finish the paper]

b. whether [IP POS [John finished the paper]] or [IP not [John finished the paper]]

c. whether [POS $e_{i}$ ] or [not $e_{i}$ ] [John finished the paper $]_{i}$

Another possible approach is that the second disjunct or not moves and adjoins to whether after ellipsis has taken place, as illustrated in (97).

(97)a. ... whether [IP John finished the paper] [or [IP not finishe the paper]]

b. ... whether [or [IP John not finished the paper] $]_{i}$ [IP John finished the paper] $t_{i}$

18 Two comments are at issue concerning (94). First, Schwarz (1999) observed that, although right-node raising from within VP to above IP is degraded both for full phrases and for particles, it is slightly less degraded for the former than for the latter. Native speakers that we consulted verified this intuition for (94) and (67a). Second, note that the deletion in (94) does not include the verb, but just the subject, unlike typical gapping cases. Schwarz argues that such examples do not actually involve deletion of subjects, but rather missing pronominal subjects that are anaphoric to the subject in the first disjunctive clause. See Schwarz for further discussion of missing subjects in examples like (i):

(i)a. Either [IP someone stole your hat] or [IP took it thinking it was his]. (Schwarz 1999, ex. 68b). 


\section{CONClusion}

To conclude, we have argued for a hybrid movement and ellipsis analysis for the syntax of whether $/ Q \ldots$ or constructions. By arguing that whether $/ Q$ undergoes movement, whereas either does not, we were able to extend the ellipsis analysis of either ... or to whether/ $Q \ldots$ or, unifying their syntax, and yet explain the apparent asymmetries between the two types of constructions. Given that whether/Q is a $w h$-form of either, the syntactic parallelism between the two types of constructions is a welcome result. The combined ellipsis and movement analysis of whether/Q $\ldots$ or also captures the $w h$-movement (or $w h$-scoping) characteristics - sensitivity to islands, scoping mechanism in Hindi - and the ellipsis properties string syntax in Hindi and Korean, case marking in Korean, focus pattern in English - of whether/Q ... or constructions.

\section{REFERENCES}

Bresnan, Joan. 1974. 'Position of Certain Clause-Particles in Phrase Structure', Linguistic Inquiry 5, 614-619.

Dayal, Veneeta. 1996. Locality in WH Quantification, Kluwer Academic Publishers, Dordrecht.

Dayal, Veneeta. 2000. 'Scope Marking: Cross-Linguistic Variation in Indirect Dependency', in Uli Lutz, Gereon Müller, and Arnim von Stechow (eds.), Wh-Scope Marking, Vol. 37 of Linguistics Today, John Benjamins Publishing Company, Amsterdam/Philadelphia, pp. 157-193.

Groenendijk, Jeroen and Martin Stokhof. 1984. 'Studies in the Semantics of Questions and the Pragmatics of Answers', Ph.D. thesis, University of Amsterdam.

Han, Chung-hye and Laura Siegel. 1997. 'Syntactic and Semantic Conditions on NPI Licensing in Questions', in Brian Agbayani and Sze-Wing Tang (eds.), Proceedings of West Coast Conference in Formal Linguistics, Vol. 15, CSLI Publicatins, Stanford, pp. 177-191.

Hankamer, Jorge. 1971. 'Constraints on Deletion in Syntax', Ph.D. thesis, Yale University. Higginbotham, James. 1993. 'Interrogatives', in Ken Hale and Samuel Jay Keyser (eds.), The View from Building 20: Essays in Linguistics in Honor of Sylvain Bromberger, MIT Press, Cambridge, MA, pp. 195-227.

Hudson, Richard. 1976. 'Conjunction Reduction, Gapping, and Right-Node-Raising', Language 52, 535-562.

Jespersen, Otto. 1909-1949. A Modern English Grammar on Historical Principles, Allen and Unwin, New York.

Johnson, Kyle. 1996. 'Gapping', Unpublished manuscript, University of Massachusetts, Amherst.

Karttunen, Lauri. 1977. 'Syntax and Semantics of Questions', Linguistics and Philosophy 1, 3-44.

Kayne, Richard. 1998. 'Overt vs. Covert Movement', Syntax 1(2), 128-191.

Kroch, Anthony and Ann Taylor (eds.). 2000. Penn-Helsinki Parsed Corpus of Middle English, 2nd edn, Department of Linguistics, University of Pennsylvania, Philadelphia. Accessible via www.ling.upenn.edu. 
Ladusaw, William. 1980. Polarity Sensitivity as Inherent Scope Relations, Outstanding Dissertations in Linguistics, Garland Publishing, New York.

Larson, Richard. 1985. 'On the Syntax of Disjunction Scope', Natural Language and Linguistic Theory 3, 217-264.

Levine, Robert. 1985. 'Right Node (Non-)Raising', Linguistic Inquiry 16, 492-497.

McCawley, James. 1982. 'Parentheticals and Discontinuous Constituent Structure', Linguistic Inquiry 13, 91-106.

Neijt, Anneke: 1979, Gapping: A Contribution to Sentence Grammar, Foris, Dordrecht.

Postal, Paul. 1974. On Raising. MIT Press, Cambridge, MA.

Radford, Andrew. 1997. Syntactic Theory and the Structure of English: A Minimalist Approach, Cambridge University Press, Cambridge.

Reinhart, Tanya. 1991. 'Elliptic Conjunctions - Non-Quantificational LF', in A. Kasher (ed.), The Chomskyan Turn, Blackwell, Oxford, pp. 360-384.

Roberts, Craige. 1996. 'Information Structure in Discourse: Towards an Integrated Formal Theory of Pragmatics', in J.-H. Yoon and Andreas Kathol (eds.), OSU Working Papers in Linguistics 49: Papers in Semantics, Department of Linguistics, Ohio State University, pp. 91-136.

Romero, Maribel. 1998. 'Focus and Reconstruction Effects in Wh-Phrases', Ph.D. thesis, University of Massachusetts, Amherst.

Rooth, Mats. 1985. 'Association with Focus', Ph.D. thesis, University of Massachusetts at Amherst.

Rooth, Mats. 1992. 'A Theory of Focus Interpretation', Natural Language Semantics 1, $75-116$.

Ross, John R. 1967. 'Constraints on Variables in Syntax', Ph.D. thesis, MIT.

Ross, John. 1970. 'Gapping and the Order of Constituents', in M. Bierwisch and K. E. Heidolph (eds.), Progress in Linguistics, Mouton, The Hague, pp. 249-259.

Schwarz, Bernhard. 1999. 'On the Syntax of either ...or', Natural Language and Linguistic Theory 17(2), 339-370.

Stillings, Justine. 1975. 'The Formulation of Gapping in English as Evidence for Variable Types in Syntactic Transformations', Linguistic Analysis 13, 247-273.

Williams, Edwin. 1981. 'Transformationless Grammar', Linguistic Inquiry 12, 645-654.

Chung-hye Han

Simon Fraser University

Department of Linguistics

8888 University Drive

Burnaby, V5A 1S6

Canada

$<$ chunghye@sfu.ca>

Maribel Romero

University of Pennsylvania

Department of Linguistics

610 Williams Hall

Philadelphia, PA 19104

USA

<romero@ling.upenn.edu> 